\title{
Cesariny de pé e com os braços muito abertos: o poeta em expansão
}

Resumo: Mário Cesariny foi frequentemente instado por críticos e entrevistadores a que se definisse: é poeta ou pintor? Respondendo que não há diferença entre as duas denominações, o artista apresenta uma concepção de poesia que extravasa até mesmo a produção de qualquer objeto. Neste artigo, visitamos a bibliografia recente que se dedicou a investigar a relação entre poesia e imagem em sua obra e, em seguida, analisaremos algumas criações suas que apontam uma reelaboração da figura do poeta a partir de uma variedade de "fazeres" e que pressupõem uma desespecificação do objeto artístico e, consequentemente, do poema.

Palavras-chave: Mário Cesariny, poesia portuguesa, surrealismo, figuras de poeta, transmedialidade

Abstract: Mário Cesariny was frequently asked by critics and interviewers to define himself: did he see himself as a poet or a painter? Replying that there is no difference between those denominations, the artist presents poetry as something that is capable of exceeding the limits of the production of any object. In this article, we will observe some of the most recent studies that have approached the relationship between image and poetry in Cesariny's work. We will then analyze some of his creations that suggest a reevaluation of the figure of the poet by presenting a wide variety of "makings" that imply a de-specification of the artistic object, and, consequently, of the poem.

Keywords: Mário Cesariny, portuguese poetry, surrealism, figures of the poet, transmediality

\section{Introdução}

A ideia de que Mário Cesariny deveria escolher se deseja ser visto como poeta ou pintor revela, por parte da crítica de arte, uma vontade de separação das suas atividades que parece pressupor a primazia de uma sobre a outra. Cesariny afirmou em diversas ocasiões, porém, que "não há diferença" entre as práticas, uma vez que poesia e pintura vêm "do mesmo sítio que sou eu" (Cesariny 2020a: 203), como revela na entrevista conduzida 
por Bernardo Pinto de Almeida em 1988, no contexto da exposição O Mar-i-o Cesariny: o navio de espelhos. Anos antes, também durante uma mostra individual, a resposta dada à tão frequente pergunta trazia uma concepção de "poeta" que ultrapassava mesmo os limites do fazer artístico:

Quando se diz poeta não se diz [--] ou não se diz só [--] a pessoa que faz versos, não é? O poeta é um ser que [--] no próprio sentido verdadeiro da palavra, é um ser que faz uma coisa, não é? Portanto, podem ser versos como quadros como ... qualquer outra coisa, não é? (Cesariny 1971)

Em entrevista de 2005, apesar de reconhecer a diferença entre a pintura e a literatura, sendo a primeira "mais terapêutica" e a segunda "um grande choro", demonstra certa impaciência diante da pergunta a respeito de se ver como pintor ou poeta, apontando que a dificuldade de categorização da sua atividade no cenário português está ligada à singularidade da sua experiência artística no país:

\footnotetext{
Ai, é a mesma coisa. Isso era... Sabe há muitos anos isso foi um caso sério. Porque as pessoas diziam "este é poeta ou é pintor? É pintor ou é poeta?". Ora, felizmente há muitos casos de poetas que são pintores e de pintores que são poetas. Não cá em Portugal, mas lá fora existe muito. Quanto a mim, é a mesma coisa, sabe. (Cesariny 2005)
}

Sintoma anterior da dificuldade de nomeação dessa atividade é a obra "S.W." (1968) (Figura 1), cujo enigmático título julgamos poder ler como uma referência a South West, região de Londres onde ficou hospedado na sua marcante passagem de 1965 pela cidade. $\mathrm{Na}$ obra, Cesariny se aproveita de um certificado de inscrição no consulado de Portugal em Londres para a criação de um objeto híbrido, em que não apenas se cruzam a escrita, a pintura e a colagem, mas em que se cria também um circuito que liga a esfera biográfica da vivência na capital inglesa e o registro civil à produção artística, por meio da colagem de um documento de identidade que traz o seu nome, o nome dos seus pais, o seu estado civil, sua data de nascimento, seu endereço e sua profissão ("escritor") sobre uma pintura de manifesta liberdade formal e de experimentação plástica. A obra parece, assim, uma provocação à pergunta "este é escritor ou é pintor?", uma vez que a certidão burocrática está em declarada tensão com a superfície sobre a qual é colada. 


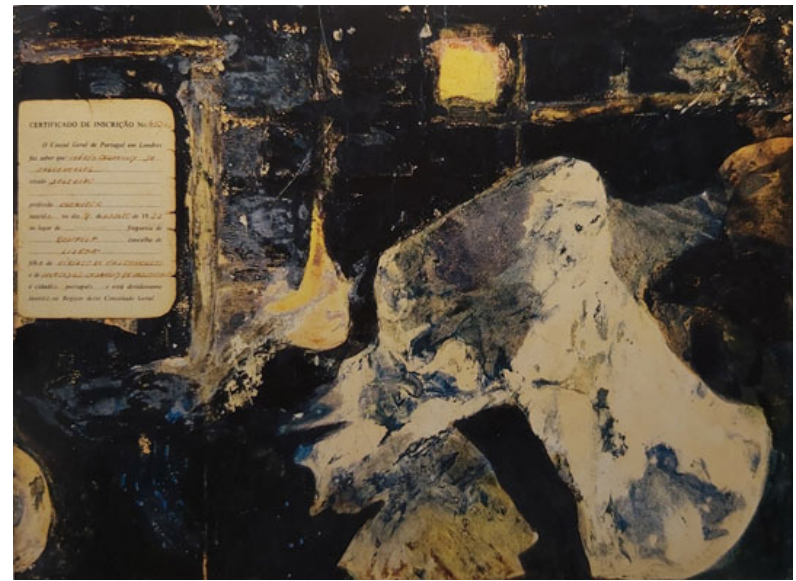

Figura 1 - "S.W.” (1968), Mário Cesariny. Têmpera, tinta-da-china e colagem s/ papel colado em platex, 51 x 38 cm. Coleção J.P.F.

Se, como aponta Teresa Ferreira (2019: 74) a respeito de "S.W.", "[e]sta construção por via de um dispositivo identificativo constitui uma estratégia autorretratística que produz o efeito indicativo de uma pessoa determinada por meio do objeto artístico", Cesariny parece jogar justamente com a impossibilidade de se fixar uma imagem ou identidade do artista nos moldes de declarações oficiais pré-preenchidas. Por esse motivo, a resposta à lacuna "profissão" não dará jamais conta da dimensão da sua atividade.

Um modo de superação da dificuldade de nomeação da sua prática artística parece residir na possibilidade de olhar para Mário Cesariny como um caso de artista de "ofício múltiplo". Uma tal abordagem nos permitiria, por um lado, evitar uma visão "compartimentada" de sua obra, que pressuporia uma distinção disciplinar das suas atividades entre as artes plásticas e a literatura, e, por outro, nos estimularia a investigar os aspectos híbridos dessa produção e a iluminar a sua potência de atravessamento de fronteiras entre as artes. Como apontam Joana Matos Frias, Pedro Eiras e Rosa Maria Martelo em sua introdução a Ofício múltiplo: poetas em outras artes (2017), com a expressão escolhida, pretendem caracterizar obras nas quais as relações interartísticas se dão entre "objectos produzidos pelo mesmo Autor" e, assim, "descrever o recurso destes criadores a uma pluralidade de meios criativos" (Frias et alii 2017: 7).

A "obra única" de Cesariny tem, na multiplicidade e na pluralidade de linguagens pelas quais transita, suas mais fundamentais características. A defesa de uma abordagem de sua produção "como um todo" tem sido feita por críticos como João Lima Pinharanda, Bernardo Pinto de Almeida, Perfecto Cuadrado, António Gonçalves e, mais recentemente, por Michele Coutinho Rocha e Emília Pinto de Almeida, cujas investigações apontam a exigência de uma crítica que sublinhe a "heterogeneidade constitutiva" (Almeida 2017: 40) da obra sobre a qual nos debruçamos. Os críticos elencados defendem, assim, uma 
abordagem que afaste leituras que segmentem a obra de Cesariny em termos de "uma obra plástica" e "uma obra escrita", insistindo na pouca produtividade que há na tentativa de definir se se trata de um poeta que pintava ou de um pintor que escrevia poemas, uma vez que seu fazer "envolve a interpenetração, a reconversão, a coalescência de domínios ou suportes, e a emergência de soluções poemáticas declaradamente híbridas" (ibidem). A dificuldade de nomeação é, portanto, um traço do pioneirismo da atividade cesarinyana também em relação aos estudos interartes.

Recolhemos, a seguir, as diferentes abordagens que têm sido feitas nesse sentido. Posteriormente, analisaremos a expansão da ideia de poesia em Cesariny a partir de algumas obras que apontam uma reelaboração da figura do poeta a partir de uma variedade de "fazeres" e que pressupõem uma desespecificação do objeto artístico. Assim, veremos como os conceitos de poeta e de poesia elaborados pelo artista assentam num princípio corporal, vital e dinâmico de um fazer no mundo que, no limite, prescindiria da produção de qualquer artefato.

\section{Poesia e imagem}

As soluções que têm sido encontradas nos últimos anos pelos críticos para a realização de uma análise que compreenda a obra de Cesariny como um todo podem ser divididas, grosso modo, em torno de duas formas de se aproximar da sua prática artística. Há quem defenda uma leitura atenta aos processos de combinação intermedial nas obras híbridas, tais como os pictopoemas e os poemas-colagem, mas também na relação entre as pinturas e os seus títulos, em busca das confluências e correspondências entre o uso da palavra escrita e da imagem tomada em sua dimensão visual, como é o caso mais destacado de Rocha (2017/2018) e de Cuadrado (2004). Uma outra via possível para a compreensão da obra sob uma única perspectiva é aberta pela percepção de que a ideia cesarinyana de poesia está ligada à de imagem "à revelia de qualquer cisão disciplinar" (Almeida 2017: 39), isto é, pensando que a poesia não deve ser tomada apenas como uma arte das palavras, assim como a imagem não deve ser percebida exclusivamente em seu caráter visual e material, como defende Emília Pinto de Almeida (2017). Nota-se, assim, que os caminhos percorridos para lidar com as relações interartísticas nessa obra dividem-se por considerarem dois modos distintos de se compreender os termos "poesia" e "imagem", sendo um atento às fronteiras disciplinares entre literatura e artes plásticas - apesar de apontar que a obra de Cesariny atravessa esses mesmos limites - e o outro, a um conceito abstratizante das expressões. É necessário, portanto, perceber que os usos do termo "imagem" na poesia e na crítica não acontecem na "base de um entendimento unívoco", como aponta Martelo (2012: 16) em artigo no qual analisa as diferentes concepções de imagem mobilizadas pela crítica portuguesa nos anos de 1960 . $\mathrm{Na}$ abordagem de uma obra como a de Cesariny, portanto, é preciso pôr às claras o que se pretende referir com o seu uso. 
Michele Rocha (2018) chama a atenção para o modo como, nos poemas-colagem do artista, os fragmentos de texto colados sobre os papéis adquirem visualidade plástica. A distribuição espacial e as diferenças de cor, fonte e tamanho dos caracteres condicionam o olhar e criam hierarquias na leitura (Rocha 2018: 9). Da mesma forma, avalia como a inclusão de signos visuais nas colagens se relaciona com os fragmentos textuais. A autora pretende mostrar, assim, que "a imagem enfatiza o significado das palavras e as palavras explicitam o conteúdo da imagem" (Rocha 2018: 11), como aponta a propósito da colagem "Sur la mort" (1947) (cf. Cesariny 2020b: 498). Percebe-se, no seu trabalho, que Rocha parte de uma consideração da poesia em sua dimensão textual-linguística e da imagem dentro dos limites materiais-visuais. Seu objetivo é apontar que a "linguagem poética" deve ser entendida por si só como "um conceito abrangente", capaz de acolher múltiplas formas de expressão (Rocha 2018: 7). A poesia é, assim, percebida como a linguagem artística por excelência, posto que é aquela para a qual convergem - e na qual se integram - as demais.

Essa abordagem é semelhante à realizada por Perfecto Cuadrado no estudo intitulado "Palavra/Imagem: Confluências" (2004), em que investiga as muitas dimensões das relações entre escrita e visualidade na obra de Cesariny. Para esse fim, Cuadrado aponta a existência seja de caminhos confluentes nesse domínio, como a significação do vazio nas páginas por efeito do espaçamento das palavras sobre a superfície desenvolvida por Mallarmé em Un coup de dés jamais n'abolira le hasard (1897), seja de relações de influência mais direta sobre a produção cesarinyana, como é o caso dos pictopoemas de Victor Brauner. $\mathrm{O}$ autor sublinha igualmente o estabelecimento de diálogos interartísticos nas obras - o que chama de "intertextualidade plástico-verbal” (Cuadrado 2004: 225) -, pelo recurso a outros sistemas de escrita, como a partitura musical, ou pela citação textual de outros artistas realizada em forma de palavra escrita pintada sobre as superfícies e nos títulos escolhidos para as produções. ${ }^{1}$ Apontando que a integração de variadas linguagens pode se articular à constituição de uma grande Obra sonhada pelos "artistas da Modernidade" (Cuadrado 2004: 217), o crítico destaca ainda que, para Cesariny como para o Surrealismo das décadas de 1950 e 1960, a "poesia figurada" estava ligada a uma tradição da magia e do pensamento esotérico que encontra ressonância também no seio da Modernidade artística. Com o vínculo à dimensão mágica estariam em jogo, portanto, temas como "a questão do transcendentalismo (ou não) do acto da criação (digamos 'poesia'), da importância (muita, pouca ou nenhuma) da intervenção demiúrgica do autor e do valor simplesmente referencial ou também genesíaco do verbo" (Cuadrado 2004: 220). Para ele, importa salientar sobretudo que a obra de Cesariny transporta um projeto de totalidade que busca apagar as fronteiras entre a produção literária e a plástica, sendo as muitas maneiras de confluência entre a palavra e a visualidade um modo de constituição de uma "mesma unidade significativa".

Nas abordagens de Rocha (2018) e de Cuadrado (2004), a compreensão da obra de Cesariny como uma "unidade" depende de um alargamento da ideia de poesia, em que esta passa a comportar linguagens artísticas pertencentes a outros campos disciplinares, 
como a música e as artes plásticas, mas que deriva mais propriamente de uma associação entre a palavra (ou fragmentos seus) e a imagem visual. Esse pensamento encontra eco na definição bretoniana de "poema-objeto": "uma composição que tende a combinar os recursos da poesia e das artes plásticas e a especular sobre o seu poder de exaltação recíproca" (Breton 1979 [1942]: 284), ${ }^{2}$ isto é, em que a palavra escrita e a visualidade entram em um circuito de retroalimentação significativa. Do ponto de vista dos críticos mencionados, percebe-se uma busca por desfazer as cisões operativas entre poesia e imagem ao apontar que a visualidade é tomada por Cesariny como condição indissociável da poesia.

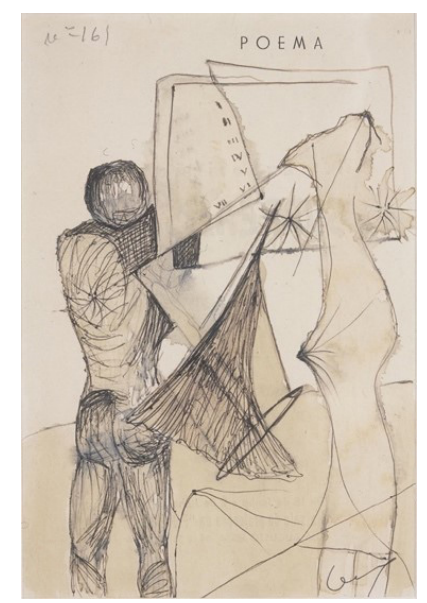

Figura 2 - Sem título (“Poema”), 1949. Aguada e tinta-da-china s/ papel 21,3 x 14,4 cm, Colecção Fundação Cupertino de Miranda

As análises empreendidas por ambos ligam, portanto, a ideia de poesia à de poema e estas à imagem plástica. Essa relação não é estranha ao artista em questão, manifestando-se mesmo quando Cesariny opta pelas denominações "pictopoemas", "poema-colagem”, ou, simplesmente, "poema", para se referir tanto às criações híbridas quanto àquelas em que não há sequer a presença de palavras. Uma obra como o desenho sem título de 1949 (Figura 2) pode servir como exemplo dessa operação. Nele, vemos em posição de título a palavra "Poema", a que se segue não uma composição verbal, mas visual. O desenho adquire outra dimensão devido ao fato de ter sido produzido abaixo da palavra "poema" que vinha impressa sobre o verso da capa do catálogo da I Exposição dos Surrealistas, acontecida em Lisboa, em 1949. De fato, a folha trazia a sugestão de intervenção por ser composta de um título - "POEMA" - a que se seguia o espaço em branco. A opção de Cesariny por um desenho em lugar de versos aponta que a concepção alargada do poema como um objeto constituído não apenas de palavras já se fazia presente pelo menos desde o final da década de 1940 e, como se manifesta nas intervenções de outros artistas sobre os seus exemplares do catálogo, percebemos que essa concepção era compartilhada. 
Assim, além do desenho-poema de Mário Cesariny, temos registro também dos de António Maria Lisboa, Mário Henrique Leiria, Pedro Oom, Carlos Calvet (Figura 3), Carlos Eurico da Costa e de Fernando Alves dos Santos.

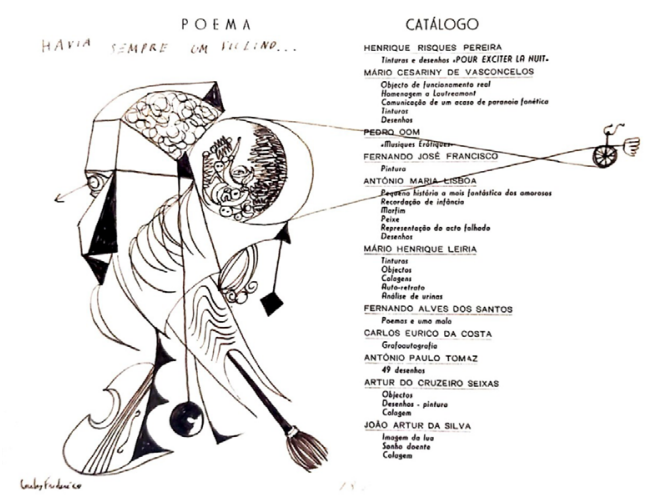

Figura 3 - "Havia sempre um violino...", 1949, Carlos Calvet. Intervenção no catálogo da I Exposição dos Surrealistas, Lisboa, 1949

Seguindo por caminho distinto, Emília Pinto de Almeida (2017) procura mostrar como Cesariny compreende a poesia como o instante mágico de aparição da imagem uma imagem que é tomada, pela crítica, para além da dimensão visual, mas não se prende exclusivamente à imagem retórica. Dessa maneira, o trabalho de Almeida lida com um conceito de imagem que transita entre o "sensível e o inteligível, o visível e o invisível" (Almeida 2017: 40) e se baseia numa ideia de poiesis como invenção de imagens livres. A imagem não se limita, portanto, aos modos de criação da imagem poética tais como a metáfora e a analogia, tampouco se liga a uma vocação mimética da pintura.

A vantagem de uma leitura como a de Almeida se deve, em grande parte, pelo fato de a autora recorrer às reflexões do próprio artista sobre as relações entre imagem e poesia. Nesse passo, observa também o modo como as formulações de Cesariny a respeito da pintura de outros artistas pode nos auxiliar a perceber como essas reflexões se dão na sua prática artística. Destaca-se, aí, a referência à pintora Vieira da Silva - com quem estabeleceu um dos mais iluminadores diálogos para a compreensão da sua obra ${ }^{3}$ - como uma poeta, e a descrição do seu ofício como "fazer imagem", revelando que a poesia e a imagem são compreendidas como conceitos polivalentes e transmediais (Clüver 2006 / Rajewsky 2018), mas equivalentes entre si, de modo que poesia e imagem sejam sinônimos. Como escreve, "segundo essa concepção, 'quadro ou poema' respondem a um imperativo comum, porém indeterminado, 'fazer imagem', e é ele que parece solicitar a possibilidade da poesia, do fazer, qualquer que seja a sua expressão” (Almeida 2017: 44).

Para além da recolha da reflexão crítica produzida pelo artista a respeito da sua ideia de imagem, a autora procura delinear os conceitos cesarinyanos por meio dos aquamotos, 
pinturas normalmente feitas com tinta-da-china sobre papel que, com a tinta ainda fresca, são submersas em água ou têm água derramada sobre sua superfície. Nessas obras, uma pintura inicial, feita sob o controle da mão do pintor, será afetada inteiramente pelo gesto interventivo que convoca o acaso. O momento em que a imagem irrompe não pode ser apreendido quer nos poemas e quadros - meros vestígios do acontecimento -, nem sequer pelo próprio poeta, o "fazedor de imagens" (Cesariny apud Almeida 2017: 44). Este, assim como as obras resultantes, são testemunhas do lampejo da faísca criadora da Poesia. A imagem é, portanto, “o excedente poético, que interrompe, ou 'suspende' [...] a premeditação técnica envolvida na feitura de cada obra" (Almeida 2017: 45).

Os aquamotos, as sismofiguras e as figuras do sopro (ou soprofiguras), práticas de pintura e desenho inventadas e praticadas por Cesariny, em sua "espécie de experimentalismo selvagem" e sua "vontade furiosa de desregrar a abordagem ao quadro", como as caracterizou Bernardo Pinto de Almeida (2005: 16) atuam no limite da tensão entre o controle da mão do artista e a possibilidade de intervenção do acaso e de abandono ao automatismo. A imagem que aparece e que irrompe nesse momento será, assim, concebida como "aquilo que escapa à pura intencionalidade do artista e, nessa medida, equivale a um excesso sobre os seus desígnios e eventuais planos” (Almeida 2017: 47).

A negociação entre a pintura e a despintura nessas e noutras experiências a favor desta última certamente ecoa sua autoafirmação poética como um surrealista, pelo que tem de automatismo, de experiência de desregramento dos sentidos e também de potência erótica - a qual não nos deixa esquecer que o pintor não se limita à posição de espectador distanciado da própria criação, sendo as obras produzidas nesses contextos frutos de acaso vigiado e de um esforço reiterado em favor do abandono contra a vigília consciente. Desse modo, a atividade é como um jogo de trapaça constante entre a intenção e a participação consciente do artista, de um lado, e o automatismo e o acaso, do outro. Num comentário sobre os aquamotos, recolhido por E. Almeida (2017), Cesariny delineia o que implicaria levar às últimas consequências a intervenção do imprevisto que se manifesta no derramamento de água sobre a pintura. Substituindo a tinta-da-china pela tinta a óleo e a dissolução em água pelo diluente inflamável, o artista dá a ver a violência da tensão destrutiva do gesto e a consciência de lidar com o risco de incêndio:

[A "sismofiguragem"] é de algum modo a 'maneira seca' dos meus aquamotos, que tampouco têm sido levados até ao esgotamento. Não podem, não posso. Gostaria de fazê-los a óleo sobre grandes superfícies, o que requereria um atelier imenso protegido contra o fogo e grandes bidons, talvez grandes camiões 'Esso' carregados de diluente e de mangueiras ejectoras. Só possível talvez nos Estados Unidos. Estes 'aquamotos', transformados em benzinas motoras das formas poderiam, como os outros, ser simples (puros), ou compostos (auxiliados, interferidos). (Cesariny apud Almeida 2017: 47) 
A reavaliação dos conceitos de imagem e de poesia resulta, seguindo o pensamento de E. Almeida (2017), numa compreensão da imagem que ultrapassa os limites da imagem material-visual e pictórica e da poesia como uma arte de palavras. A autora aponta que, apesar de aquilo a que chama "imagem" enquanto sinônimo de "Poesia" se realizar à revelia da obtenção da imagem plástica nos quadros, sua origem não pode ser localizada antes desse momento. Evidencia-se, aos nossos olhos, que, ainda que não traga $a$ priori a "obra pronta em seu espírito", segundo uma perspectiva romântica de Poesia, a obra de arte tornada objeto autônomo e independente do gesto de criação tampouco pode ser vista como o objetivo final do impulso artístico. É entre os dois que se encontra a Poesia-imagem: na convocação do acaso por meio da gesticulação desatenta com os materiais, no acontecimento, no movimento e na ação poética.

\section{0 poeta em expansão}

A concepção que E. Almeida apresenta muito se aproxima do depoimento dado por Cesariny na década de 1970 que destacamos acima, no qual define o poeta como "um ser que faz uma coisa", independentemente de a "coisa" ser um poema, uma pintura ou "qualquer outra coisa". Nesse sentido, se a poesia é um fazer, o poeta é o seu fazedor formulação que também sublinha E. Almeida. A ideia de poesia de Cesariny, portanto, é abrangente o suficiente para transitar não apenas entre diferentes campos de expressão artística, sejam eles a pintura, a poesia escrita e as práticas combinadas, mas também por qualquer forma de "fazer", residindo aí a sua potência performática, na qual importa tanto ou mais do que o objeto resultante - o próprio ato, a disposição ao fazer no mundo.

Num poema como "arte de inventar os personagens", do livro Manual de Prestidigitação (1956), podemos perceber a mesma defesa da disponibilidade à criação e à invenção que não se prende a um ofício específico, tampouco a uma relação com materiais usuais para a produção do "poeta ou pintor", como a caneta, a máquina de escrever, a tinta, o pincel, ou o papel, apontando diretamente para a relação entre a criação poética e a adoção de uma postura pelo corpo do criador, que se volta para o mundo:

arte de inventar os personagens

Pomo-nos bem de pé com os braços muito abertos

e olhos fitos na linha do horizonte

Depois chamamo-los docemente pelos nomes

e os personagens aparecem.

(Cesariny 2017: 143)

O poema pode ser pensado como mais uma de muitas artes poéticas de Cesariny, sendo a vertente metapoética e autorreferencial uma constante que atravessa a sua obra. ${ }^{5}$ As "artes de" passam adiante um ensinamento do "como fazer", de modo que haja 
uma "coincidência entre a demonstração da maneira de funcionamento de uma prática de escrita e o desejo de formação de um novo leitor" (Lessa 2017: 22). Aqui, porém, não se trata de uma prática de escrita, ainda que haja uma referência ao poder do chamamento e da nomeação, mas de uma invenção que extrapola os limites materiais da arte literária ou da feitura de qualquer objeto. As ideias subjacentes à publicação de 1956 de que a poesia é uma prestidigitação, o poeta, um prestidigitador, e de que é possível fazer dessa prática um manual sugerem que não é o objeto que aparece aquilo que realmente interessa, senão o ato de fazer aparecer. Além disso, redimensionam os aparatos necessários para a criação poética que esperaríamos descritos. As instruções para a criação dos personagens que o poema traz são, assim, avessas ao lugar comum do escritor ou do pintor sentado, dobrado sobre um papel ou diante de uma tela, com as mãos ocupadas com o pincel, a caneta ou as teclas da máquina de escrever. Para aprender a reproduzir essa arte poética, é preciso adotar outra disposição corporal: de pé, braços abertos, olhos na linha do horizonte.

O poema instrui também acerca de uma prática de invocação que conjuga a nomeação como maneira de fazer aparecer os personagens à invenção destes e a um transbordamento do domínio da criação artística para o seu aparecimento no mundo. A invenção poética não se circunscreve ao papel, mas é exposta como algo que pode ser executado fora desse domínio, pautando-se a nomeação num princípio genésico (ou performativo) do verbo e num princípio corporal performático (Taylor 2003), dependente de uma situação e de um enquadramento específico para que tenha sucesso. ${ }^{6}$

Para seguirmos à risca as instruções que o poema fornece ao leitor, é preciso que se observe uma série de condições não-discursivas para o sucesso da nomeação, apontando a dimensão performática da criação cesarinyana. Assim, se a arte poética acima é não apenas uma abertura à aprendizagem de um modo de inventar e de fazer aparecer a imagem, mas também um ensinamento de um modo de se pôr diante dessa obra, ela nos ensina a deslocar a atenção da sua dimensão discursiva para considerarmos o cenário quase ritualístico que é evocado pela sugestão da postura corporal que deve ser adotada, da inflexão da voz, do modo de olhar e do lugar onde isso deve ser feito, apontando, pelo uso da primeira pessoa do plural, que essa prática pode ser coletiva.

Contemporânea à publicação do poema, a fotomontagem "O poeta" (Figura 4), que, conforme consta no livro Mário Cesariny (1977), data de 1956, e que, em 1969, foi transformada em “'O poeta em 1958' ou 'Porque motivo Picasso não quer voltar a Espanha?'” (Figura 5), aponta também caminhos para a compreensão desse fazer expansivo da poesia. No volume de 1977, a obra é legendada como sendo uma "capa de catálogo", produzida no ano de 1956 (Cesariny 1977: 103). A exposição em que Cesariny participou como artista nesse período e que justificaria a reprodução da obra como capa foi a Exposição de Capas-Poemas-Objectos para o livro A verticalidade e a chave de António Maria Lisboa, em 1956, na capital portuguesa. ${ }^{7}$ Para essa mostra, temos notícia de o artista ter produzido também a capa-poema-objeto "Como um ser inorgânico" (1956). A respeito da primeira edição do 
livro de António Maria Lisboa, realizada pela editora Contraponto em 1956, obtemos as mais completas informações na correspondência entre Cesariny e Cruzeiro Seixas:

Está composto, impresso, dobrado e cozido - definitivamente pronto - o poema A Verticalidade e a Chave, do António Maria Lisboa, dedicado a Rimbaud. Vem numa edição magnífica, incluindo um desenho teu, a todo o tamanho do volume - é uma daquelas 3 homenagens ao António Maria Lisboa, que há tempos me mandaste - e com capas-objectos-colagens de autoria deste teu humilde servidor. (Cesariny 2014: 126) [Carta de 23-06-1956].

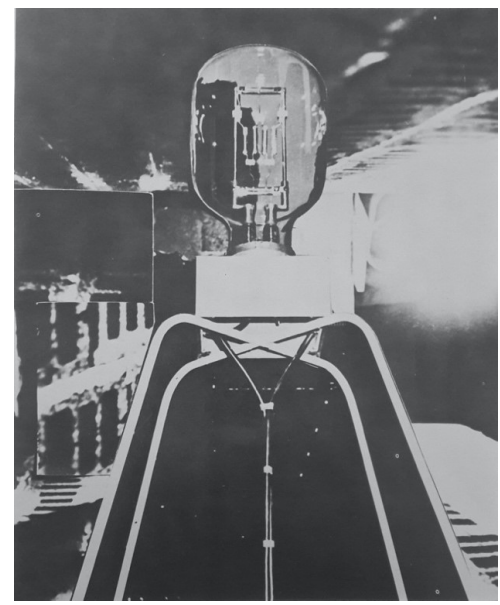

Figura 4 - “O poeta”, 1956, fotomontagem no volume Mário Cesariny (1977)

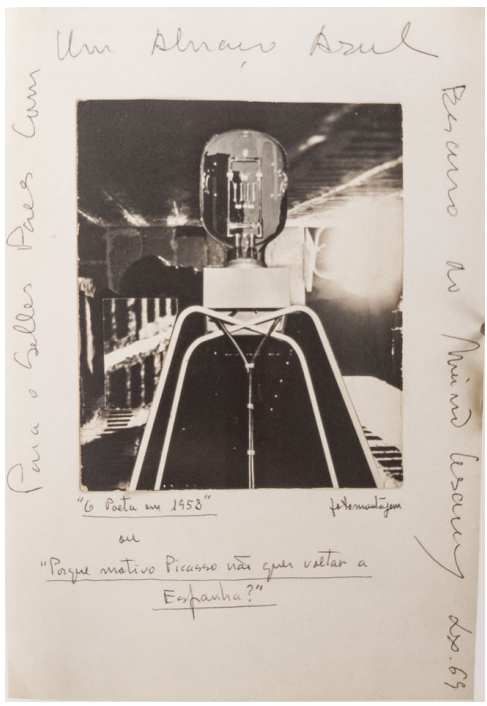

Figura 5 - “'O poeta em 1958' ou 'Porque motivo Picasso não quer voltar a Espanha?'”, 1969, fotomontagem colada em página de livro, 29,9 × 21 × 3,2 cm, Coleção Joaquim Villas-Boas 
Nas colagens, aquilo que identifica o poeta, novamente, não é a escrita, tampouco a fala ou a nomeação, sendo "poeta" um termo que é empregado para se referir a uma atividade que atravessa fronteiras entre mídias - transmedial, na definição de Clüver (2006 [2001]) e na de Rajewsky (2018), que o toma como operador crítico fundamental de análise de fenômenos que ocorrem de maneira atravessada em meios diferentes. A construção de uma máquina antropomorfa, com braços feitos do que parecem ser pernas de uma cadeira e a cabeça representada por uma lâmpada, reaproveita o tema do corpo-assemblage já explorado em um desenho como "Projecto de indivíduo para pequenas voltas" (1949). Agora, porém, o recurso às imagens fotográficas e à montagem convoca análises mais detidas sobre os objetos que compõem esse corpo, bem como permite a observação de um outro tipo de relação entre a figura do poeta que se apresenta e o seu modo de agir no mundo. Nela e no desdobramento da década seguinte, destacam-se não apenas os elementos escolhidos para a feitura do corpo maquinal que julgamos ser o do poeta anunciado pelo título. É a fotomontagem enquanto procedimento plástico que apontará para uma compreensão do poeta como um montador, um deslocador de imagens e um reorganizador do mundo e, também, da sua obra, como manifesta o retorno à colagem, em 1969. Ao trazer Picasso no título em forma de pergunta que então atribui à obra, o artista contribui para uma maior evidenciação da montagem ou da assemblage como práticas que caracterizam a atividade poética para além do campo da escrita.

Estamos diante de uma iconografia pessoal do artista como montador que depende e deriva de um dispositivo plástico como o da colagem, em que estão implicadas as ideias de montagem, redistribuição, corte e deslocamento, uma vez que, como propôs William Rubin (1966), na arte moderna e na prática de surrealistas como Joan Miró e André Masson - pertencentes a uma corrente abstratizante ligada ao automatismo com a qual se pode identificar a obra de Cesariny -, se torna cada vez mais difícil separar a estrutura plástica da iconografia (Rubin 1966: s/p). ${ }^{8}$

Um dos efeitos conseguidos pela fotomontagem de Cesariny pode ser percebido em articulação à maneira como o procedimento é utilizado em diferentes obras das vanguardas. Entender a sua utilização, segundo propõe Peter Bürger (1993), contribuiria mesmo para a elaboração de uma teoria da vanguarda. Como sublinha esse autor, um mecanismo como o da montagem é distinto das demais técnicas de pintura praticadas desde o Renascimento por incorporar "fragmentos de realidade na pintura, ou seja, de materiais que não foram elaborados pelo artista. Assim se destrói a unidade da obra como produto absoluto da subjetividade do artista" (Bürger 1993: 128). Do mesmo modo, Rosalind Krauss, em artigo dedicado ao potencial fotográfico do surrealismo, aponta que, apesar de a fotomontagem não ter sido um procedimento adotado de maneira intensa pelos surrealistas, quando ela emerge associada a outros movimentos de vanguarda, é "compreendida como um modo de infiltrar uma mera imagem [picture] da realidade com o seu significado. Isso era alcançado com a justaposição: imagem com imagem, imagem com desenho, ou imagem com texto" (Krauss 1981: 19). ${ }^{9}$ A confluência entre a dimensão plástica e a 
iconográfica é também assinalada por Krauss em sua análise de uma fotomontagem da autoria de André Breton. Para a autora, é preciso olhar para o suporte e o tecido sobre o qual se cria a imagem, isto é, "para o próprio medium da montagem” (Krauss 1981: 19).

Sublinha-se, portanto, a necessidade de se analisar a montagem de Cesariny a partir desse encontro. Uma imagem que podemos destacar é a cabeça escolhida para compor o corpo-máquina do poeta. Estamos diante da lâmpada de 75 mil watts produzida pela General Electric em 1954, em comemoração dos 75 anos de criação da primeira lâmpada incandescente comercializável por Thomas Edison. Provavelmente recortada de uma reportagem que anunciava justamente a fabricação do que era então a "maior lâmpada do mundo", não nos parece arbitrária a seleção da imagem desse objeto específico. Com uma potência equivalente à de 1250 lâmpadas de 60 watts, se estivesse ligada, a luz projetada de apenas uma fonte seria de uma tal magnitude que se provaria insuportável à vista humana. Assim, a lâmpada está apagada e a fonte de luz que aparece na composição provém de uma outra luminária, ao fundo, incapaz de iluminar plenamente o ambiente.

A luz secundária que "não ilumina realmente os objetos" e o poder luminoso do poeta que se anuncia pela cabeça-lâmpada pode nos levar diretamente a "poema", de Pena capital, do qual destacamos a segunda estrofe:

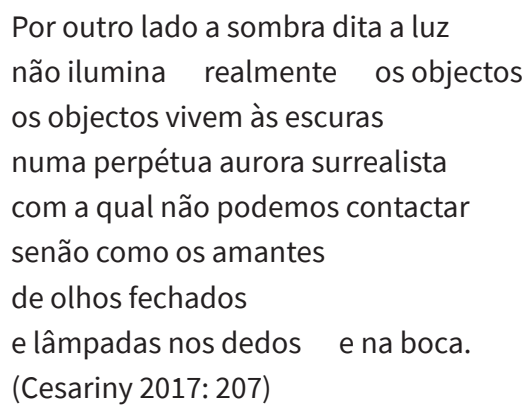

Diana Vasconcelos (2009) propõe também uma comparação entre o poema do qual destacamos esses versos e a obra revista por Cesariny em 1969. Para a pesquisadora, "a imagem da lâmpada que surge no poema sugere precisamente um Conhecimento que surge enquanto vislumbre e não como resultado de um raciocínio" (Vasconcelos 2009: 22), ligando-se à capacidade do poeta de ver sem que recorra ao órgão visual, conclusão que a leva a uma articulação com a fotomontagem e com as ideias de inspiração e de epifania. Acreditamos, porém, que, ao sabermos da potência violenta da luz emitida pela lâmpada que o encabeça, todo o corpo do poeta se transfigura e a relação com a visão e a luminosidade é perturbada. Se antes julgávamos ver apenas o tronco antropomórfico, os braços e a cabeça da máquina-poeta, agora vemos adquirirem uma aparência algo aracnídea e amedrontadora os braços e as pernas da figura montada. Percebemos, também, que olhamos para ela de baixo, como se, no cômodo limitado em que se encontra e diante 
de nossa pouca estatura, o poeta se agigantasse. Os fios ligados à cabeça são como uma ameaça da iminente iluminação do espaço escuro à sua volta e do ofuscamento doloroso que provocaria para quem o olhasse de perto. Apesar de ser o objeto da colagem, não se pode olhar para o poeta aceso, senão para aquilo sobre o que ele projeta a sua luz.

Não há, porém, montagem por parte do autor no fragmento do corpo composto de braços, pernas e cabeça, pois provêm todos de um mesmo recorte de imagem, como se pode ver abaixo (Figura 6). ${ }^{10}$ Estamos diante de um mecanismo como o do objet trouvé, em que comparece o encontro ao acaso de um objeto pronto, mas de outra forma perdido, vazio de significado poético. Por meio do procedimento plástico da colagem e do recurso ao título, o poeta é apresentado não como um inventor de objetos antes inexistentes, mas como o operador de um deslocamento que leva a uma identificação de características compartilhadas entre os universos. Esse encontro se dá entre as figuras do poeta-ameaça e da maior lâmpada do mundo, apresentada sobre uma enorme estrutura de metal. Recuperando um fragmento de Novalis muitas vezes citado por Cesariny, poderíamos dizer que o poeta encarna "o mais forte condutor-isolador da corrente poética", pois é nele onde se opera o choque luminoso entre as imagens do mundo desencantado para a desocultação da imagem poética.

Apesar das diferentes posturas adotadas pelas figuras que podemos identificar com o poeta em "arte de inventar os personagens", em "poema" e nas colagens, variando entre a docilidade que deve ser adotada na performance da nomeação, a conversão do corpo em lâmpadas amorosas e a capacidade física de projetar uma luz tão forte que é capaz de cegar, a iluminação, o aparecimento erótico das imagens e a invenção carinhosa dos personagens são formas de apontar que, na obra de Cesariny, a poesia não se circunscreve a um ofício escrito ou à execução de um objeto específico, mas a um modo encarnado de fazer algo com o mundo, sendo possível prescindir até mesmo dos limites materiais implicados na ideia de obra na poética cesarinyana.

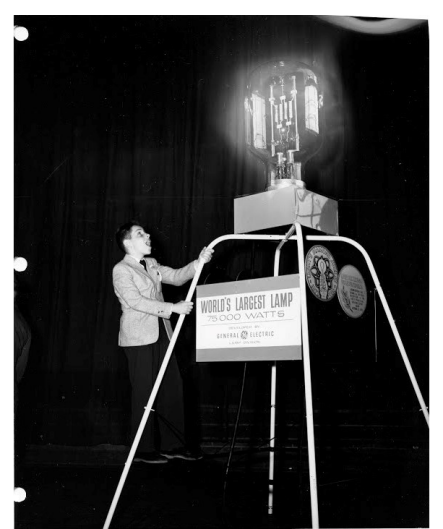

Figura 6 - Foto do miSci - Museum of Innovation \& Science. "Neil Isenberg de Schenectady, NY, boquiaberto diante da visão da maior lâmpada incandescente do mundo, 75,000 watts, que foi exibida aqui hoje quando a Companhia General Electric promoveu a reunião dos maiores acionistas do mundo (22 de abril de 1954)" 
Se recuperarmos a primeira estrofe de "poema”, poderemos perceber como a experiência corporal ocupa, nessa arte poética, papel central para o trânsito amoroso com os objetos que são iluminados:

Faz-se luz pelo processo

de eliminação de sombras

Ora as sombras existem

as sombras têm exaustiva vida própria

não dum e doutro lado da luz mas no próprio seio dela

intensamente amantes loucamente amadas

e espalham pelo chão braços de luz cinzenta

que se introduzem pelo bico nos olhos do homem

(Cesariny 2017: 207)

Braços, seio, bico, olhos, boca e dedos são as partes amorosas evocadas no corpo a corpo entre luz e sombra, entre homem e objetos. A eliminação das sombras e a iluminação dos objetos que evoca o poema são processos contínuos e perpétuos que identificam também o fazer poético, e que participam, como vimos, de um repositório metafórico que Cesariny liga ao aparecimento das imagens. Desse modo, a experiência de iluminação não é limitada à confecção de um objeto ou à escrita de um poema, tampouco à epifania ou a uma visão não-retiniana. Expande-se, antes, em direção a uma experiência, amorosa e erótica, que requer um corpo - em suas partes que ligam sentidos como o tato e o paladar à excitação amorosa "intensa" e "louca" - como lugar de encontro com objetos pré-existentes, mas antes incontactáveis.

Podemos observar as oscilações entre a iluminação e a consequente projeção de sombras, bem como uma tensão entre a ideia de movimento expansivo - que domina a primeira estrofe do poema, em expressões como processo, intensidade, loucura, espalhamento e penetração - e a de uma tendência ao estatismo e ao recolhimento - que se encontra principalmente na segunda estrofe, apresentando-se nas imagens de uma vida às escuras e de uma perpétua aurora, eterna promessa de iluminação total. A conversão do corpo em lanterna para o contato com a aurora ressoa os traços dinâmico, vital, pulsante e inquieto da prática de Cesariny, bem como a impossível equivalência entre um poema e todo o processo amoroso que está implicado na ideia de iluminação.

\section{Conclusão}

O alargamento da ideia de poesia e de poeta que observamos nos objetos analisados aqui encontra eco na defesa do artista de que a escrita é uma espécie de invocação, assim como a pintura, uma forma de terapia. Essas formulações podem ser depuradas desses e de outros objetos dos anos de 1940, 1950 e 1960, e passam por uma elaboração discursiva a partir dos anos de 1970, momento em que se distancia progressivamente da escrita de 
versos, como se a mudança de meio de expressão dominante o permitisse formular mais detidamente a relação entre as atividades. Em entrevista já de 1982, Cesariny declara:

Deixei de escrever quando percebi que as minhas coisas não passavam de literatura no sentido normativo. Não era isso que me interessava. Queria fazer uma invocação, responder a um apelo. O mais que consegui foi uma certa prestidigitação. Não a magia que procurava. (Cesariny 2020a: 155)

Com esse depoimento, o poeta aponta que os objetos resultantes não são o fim último da produção, pois a escrita, a colagem ou a pintura são concebidas como meios para alcançar ainda outra coisa que aconteceria no momento de entrega à experiência poética de iluminação de um objeto, ou de saída à rua. Dessa perspectiva, "a poesia esteve sempre na rua", ${ }_{11}^{11}$ seja pelo fato, referido em diferentes ocasiões, de que nunca escreveu um poema em casa, seja porque ela se encontra no próprio ato de saída ao mundo e não se liga exclusivamente à confecção de um "objeto" ou de uma "obra de arte".

A entrevista de 1982 a Francisco Vale é particularmente reveladora de sua concepção alargada de poesia, manifestada desde a fala que se converteu em título da publicação no Jornal de Letras, Artes e Ideias: "Não vamos dizer surrealismo. Vamos dizer poesia". Acreditamos estar em questão, aí, não um abandono do surrealismo por parte do poeta, como parece ser ecoado pelo destaque das frases do contexto em que foram ditas durante a entrevista e como parece, também, ser o intuito do entrevistador quando lhe pergunta a respeito da sua ligação com o movimento - formulada com o tendencioso advérbio de tempo "ainda": "Mas ainda se considera um surrealista?". Vista no curso da entrevista, a fala do artista revela, antes, a ligação entre as duas ideias ${ }^{12}$ :

\section{- Mas ainda se considera um surrealista?}

- Olhe, essa palavra está tão gasta, tão usada, que temos de arranjar outra. O surrealismo foi uma grande esperança. Deu grandes escritores e grandes pintores.

- Está a falar em termos de passado?

- Na minha óptica não há uma só das premissas do surrealismo que não guarde as suas virtualidades.

- Não Ihe faz impressão que o surrealismo seja hoje ensinado nas universidades como parcela da cultura oficialmente reconhecida?

- Não está. Não vamos dizer surrealismo. Vamos dizer poesia. Porque surrealismo é o que existe de mais parecido com a poesia. Não se ensina, não é possível. Tudo o que é pedagógico é muito mau. Tudo o que nasce como revolta é um tormento. O surrealismo foi um convite à poesia, ao amor, à liberdade, à imaginação pessoal. O surrealismo reuniu o romantismo, o simbolismo, o futurismo, as tradições libertárias e outras correntes, e deu-lhes um sentido. Esse sentido não vai desaparecer, ficou explícito. Aquilo a que se chamou surrealismo existiu sempre... (Cesariny 2020a: 163-164) 
Em sua resposta, o artista retoma uma concepção do surrealismo que está presente desde o Manifesto do surrealismo de 1924, em que André Breton propõe que, "considerando apenas superficialmente os seus resultados, um grande número de poetas poderiam passar por surrealistas" (Breton 1971: 38), ${ }^{13}$ avaliação à qual se segue uma longa lista de candidatos - desde Dante Alighieri e Shakespeare até Pierre Reverdy, passando pelo Marquês de Sade, por Edgar Allan Poe e Victor Hugo. Assim, Shakespeare é surrealista "em seus dias áureos", bem como "Reverdy é surrealista em casa", "Sade é surrealista no sadismo", "Poe é surrealista na aventura" ou "Hugo é surrealista quando não é tolo" (Breton 1971: 38-39).

Associada a uma perspectiva inegavelmente surrealista, a sua prática artística é apresentada diversas vezes como uma atividade vital. Como o surrealista que foi, portanto, recusa insistentemente a redução a uma concepção de escola ou movimento artístico, e defende a adoção permanente de uma atitude de intervenção no mundo, cujo intuito seria fazer "arder por completo" "a locomotiva, a estação de chegada, os raills e os passageiros" (Cesariny 1997: 89).

O fazer do poeta não se restringe à confecção de obras e à adoção de técnicas de escrita ou pintura em que se pudessem considerar "apenas superficialmente seus resultados". Pelo contrário: expande-se em direção à adoção de uma postura diante do mundo, encarnada na figura do poeta que sai à rua, seguindo a ideia de que, "com o surrealismo, a poesia fez-se olhos e ouvidos, acto testemunhado" (Cesariny 1997: 9). Ao assinalar que o surrealismo é um convite libertário, poético, amoroso e imaginativo, o poeta português se encontra também com a visão expressa por Octavio Paz, de que "[o] surrealismo não se propõe tanto à criação de poemas, como à transformação dos homens em poemas viventes" (Paz 1980: 83), , ${ }^{14}$ abolindo, com isso, a antinomia "poeta e poesia".

Trata-se, portanto, de um "exercício concreto da liberdade, isto é, de pôr em ação a livre disposição do homem em um corpo a corpo com o real”, como sugeriu Paz (1980: 32, grifos nossos). ${ }^{15}$ Como consequência direta desse "exercício", vemos os limites materiais da categoria de obra de arte postos em jogo, enquanto a dimensão de experiência vital da poesia ganha espaço. Esse gesto extrapola os limites da existência de uma "obra material" como atividade circunscrita ao campo artístico, passando a adentrar o campo performático, isto é, do campo do ato que é vivido por um "corpo nobilissimamente visível". 


\section{NOTAS}

* Maria Silva Prado Lessa é Mestra e doutoranda do Programa de Pós-Graduação em Letras Vernáculas da Universidade Federal do Rio de Janeiro. É Bolsista Nota 10 da Fundação Carlos Chagas de Amparo à Pesquisa no Estado do Rio de Janeiro (FAPERJ), desenvolvendo a pesquisa “O autoractor: Mário Cesariny e a autografia”. Sua produção acadêmica se concentra, principalmente, nos estudos de poesia portuguesa moderna e contemporânea, com destaque para a obra de Mário Cesariny.

${ }^{1}$ Um exemplo desse mecanismo é a série de pinturas apresentada na exposição 30 pinturas de Mário Cesariny Sendo 14 com Títulos Recolhidos nas "Iluminações" de Rimbaud. Na obra de Cesariny, o recurso à citação de artistas e pensadores nos títulos das obras é frequente. É essa tendência à citação e ao diálogo com outras obras, aliás, uma das linhas de força que atravessam criação plástica e escrita.

2 "Le poème-objet est une composition qui tend à combiner les ressources de la poésie et de la plastique et à spéculer sur leur pouvoir d'exaltation réciproque". Todas as traduções são nossas, exceto em casos especificados nas referências bibliográficas.

${ }^{3}$ Sobre a relação Cesariny-Vieira da Silva, remetemos ao artigo de nossa autoria, Lessa (2016) "A iluminação do real: Mário Cesariny lê Vieira da Silva", eLyra, vol. 6, nº 7, 101-116.

${ }^{4}$ Pinharanda, João Lima. “Entrevista a Mário Cesariny”. Público, “Cultura”, 7 out. 1996.

${ }^{5}$ Já tivemos a oportunidade de explorar essa dimensão em outros trabalhos: Lessa (2017), O poema como palco. Algumas cenas da escrita de Mário Cesariny, dissertação de Mestrado em Letras Vernáculas (Literatura Portuguesa), Faculdade de Letras, Universidade Federal do Rio de Janeiro, 2017; Lessa (2017), "Poema sobre palco. Cenas de Mário Cesariny", Revista do CESP, vol. 37, n 58, 11-22.

${ }^{6}$ Segundo a proposta de Diana Taylor, performativo diz respeito ao discursivo na performance, isto é, àquilo que se realiza na linguagem, no ato de fala, e que remete à teoria dos enunciados performativos proposta pela linhagem encabeçada pelo linguista J. L. Austin, em seu How to do things with words (1956) e à qual se ligam as reflexões de citacionalidade e iterabilidade dos enunciados de Jacques Derrida e dos atos performativos de Judith Butler. O termo performático, por sua vez, diz respeito ao "reino não-discursivo da performance". Como aponta a autora, essa distinção é importante porque "é vital sinalizar que os campos performático, digital e visual são separados (apesar de estarem sempre enredados entre si) do campo discursivo, tão privilegiado pelo logocentrismo ocidental" (Taylor 2003: 6).

${ }^{7}$ A partir da ligação da montagem de Cesariny com o livro de António Maria Lisboa, é possível estabelecer uma relação ainda com a obra de Rimbaud e com a ideia do poeta como um iluminador, pois, como se lê na página inicial da obra de Lisboa, “Este livro é de Rimbaud” (Lisboa 2008: 231). Esse diálogo, porém, não será explorado por este artigo.

${ }^{8}$ Em "Notes on Surrealism and Fantasy Art”, William Rubin propõe a primeira definição de "pintura surrealista". Após ter constatado que André Breton nunca formulou uma definição sumária, o autor sugere que há duas correntes entre as quais se dividem os pintores pertencentes ao movimento. De um lado, artistas como Miró e Masson representam o polo "abstrato-automático", ligado à teoria freudiana da associação livre. De outro, Dalí e Magritte comporiam a corrente "acadêmica-ilusionista", na qual prevalece o relato dos sonhos, também devedor da teoria de Freud. Ainda para Rubin, seria possível perceber, no primeiro polo, como a iconografia 
das obras deriva dos procedimentos e materiais adotados, enquanto que, em pinturas como as de Dalí, a "estrutura plástica é apenas marginalmente influenciada pela pintura moderna", residindo a potência das suas obras mais a nível iconográfico do que formal (Rubin 1966).

9 "Photomontage was understood as a means of infiltrating the mere picture of reality with its meaning. This was achieved through juxtaposition: image with image, or image with drawing, or image with text".

${ }^{10} \mathrm{NEIL}$ Isenberg of Schenectady, NY. Stands open-mounted [sic] at the sight of the world's largest incandescent lamp, 75,000 watts, which, was displayed here today when the General Electric Company held the world's largest share owners meeting. 8" x 10". 1954. miSci - Museum of Innovation \& Science. Disponível em: < https:// artsandculture.google.com/culturalinstitute/beta/u/1/asset/neil-isenberg-of-schenectady-ny-stands-openmounted-at-the-sight-of-the-world-s-largest-incandescent-lamp-75-000-watts-which-was-displayed-here-today-when-the-general-electric-company-held-the-world-s-largest-share-owners-meeting-general-electriccompany/TwHZLAupqIWKAg >. Acesso em 19 de jan. de 2021.

Sublinhe-se que, na fotografia, há uma projeção de luz sobre a lâmpada, e ela permanece desligada.

11 "A poesia está na rua" é o título de dois cartazes produzidos em 1976 pela pintora Maria Helena Vieira da Silva (1908-1992) a pedido da poeta Sophia de Mello Breyner Andresen (1919-2004) para comemoração da Revolução dos Cravos, ocorrida dois anos antes. No original de um dos cartazes, em que Vieira da Silva havia escrito "A poesia está na rua", Cesariny fez uma intervenção, escrevendo por sobre o verbo "está" a expressão "esteve sempre". Mário Cesariny, A poesia está na rua, 1976, intervenção a tinta-da-china/cartaz colado/platex. Ex-col. Mário Cesariny, Col. Fundação Cupertino de Miranda. Cf. Catálogo da exposição Correspondências - Vieira da Silva por Mário Cesariny, coord. João Lima Pinharanda e Marina Bairrão Ruivo, investigação e documentação António Soares e Sandra Santos, textos de José Manuel dos Santos, João Lima Pinharanda e Marina Bairrão Ruivo, Lisboa, Assírio \& Alvim e Fundação Arpad Szenes - Vieira da Silva, 2008, 73.

${ }_{12}$ Numa carta a Sergio Lima, Cesariny admite ter dito que não é surrealista. Como esclarece: "Em vários momentos, por coerência e liberdade minha, achei mais surrealista e outros também (repare na atitude do Pedro Oom) afirmar-me como não-surrealista diante da embrulhada do surrealismo aqui, e perante o que se supunha lá fora. Pasons." (Cesariny 2019: 30).

13 "à ne considérer que superficiellement leurs résultats, bon nombre de poètes pourraient passer pour surréalistes".

14 "El surrealismo no se propone tanto la creación de poemas como la transformación de los hombres en poemas vivientes".

15 "Se trata más bien del ejercício concreto de la libertad, esto es, de poner en acción la libre disposición del hombre en un corpo a corpo con lo real". 


\section{BIBLIOGRAFIA}

Almeida, Bernardo Pinto de (2005), Mário Cesariny. A imagem em movimento, Lisboa, Caminho.

Almeida, Emília Pinto de (2017), "Da liberdade livre das imagens: a poesia segundo M.C.V.", in Ofício múltiplo. Poetas em outras artes, Porto, Edições Afrontamento, 39-55.

Breton, André (1979), "Du poème-objet” [1942], in Le Surréalisme et la Peinture, Paris, Gallimard, 284-285.

-- (1971), Manifestes du surréalisme, Paris, NRF/Gallimard.

Bürger, Peter (1993), Teoria da vanguarda, tradução de Ernesto Sampaio, $1^{\text {a }}$ ed, Lisboa, Vega.

Cesariny, Mário (1971), “Uma Exposição: Mário Cesariny” [Entrevista concedida no contexto da exposição 30 pinturas de Mário Cesariny Sendo 14 com Títulos Recolhidos nas "lluminações” de Rimbaud, na Galeria São Mamede, em Lisboa], <https:// arquivos.rtp.pt/conteudos/uma-exposicao-mario-cesariny/> (último acesso em 20/10/2020).

-- (1977), Mário Cesariny, textos de Raúl Leal, Natália Correia e Lima de Freitas, Direcção Geral da Acção Cultural, Secretaria de Estado da Cultura, Lisboa [volume de série dedicada a artistas portugueses contemporâneos].

-- (1997), A intervenção surrealista, Lisboa, Assírio \& Alvim.

-- (2005), "Entrevista à Antena 1", <https://www.youtube.com/watch?v=wvejv68FYps> (último acesso em 10/07/2020).

-- (2014), Cartas de Mário Cesariny para Cruzeiro Seixas (1941 - 1975), edição de Perfecto E. Cuadrado, António Gonçalves e Cristina Guerra, Lisboa, Sistema Solar| Documenta e Fundação Cupertino de Miranda.

-- (2017), Poesia, edição, prefácio e notas de Perfecto E. Cuadrado, Lisboa, Assírio \& Alvim.

-- (2019), Sinal Respiratório. Cartas para Sergio Lima, edição e posfácio de Perfecto E. Caudrado, apresentação de Sergio Lima, Lisboa: Sistema Solar | Documenta e Fundação Cupertino de Miranda.

-- (2020a), Uma última pergunta. Entrevistas com Mário Cesariny (1952-2006), organizado por Laura Mateus Fonseca, Lisboa, Sistema Solar | Documenta.

-- (2020b), Poemas dramáticos e pictopoemas, edição, prefácio e notas Perfecto E. Cuadrado, Lisboa, Assírio \& Alvim.

Clüver, Claus (2006), "Inter textus / inter artes / inter media”, Aletria: Revista De Estudos De Literatura, vol. 14, n², 10-41, <https://periodicos.ufmg.br/index.php/aletria/article/ view/18067/14857> (último acesso em 8/06/2021) [O artigo é uma versão reduzida de ensaio de mesmo título publicado em 2001, in Komparatistik 2000/2001. Jahrbuch der Deutschen Gesellschaft für Allgemeine und Vergleichende Literaturwissenschaft, Heidelberg, Synchron Publishers, 14-50]. 
Cuadrado, Perfecto E. (2004), "Palavra / Imagem: Confluências", in Mário Cesariny, organizado por João Lima Pinharanda e Perfecto E. Cuadrado, Lisboa, Assírio \& Alvim, 217-226.

Ferreira, Teresa (2019), Autorretratos na Poesia Portuguesa do Século XX, tese de Doutoramento em Estudos Portugueses - Estudos da Literatura, Faculdade de Ciências Sociais e Humanas - Universidade Nova de Lisboa.

Frias, Joana / Eiras, Pedro / Martelo, Rosa Maria (orgs.) (2018), "Apresentação”, in Ofício múltiplo. Poetas em outras artes, Porto, Edições Afrontamento, 7-9.

Krauss, Rosalind (1981), "The Photographic Conditions of Surrealism", October, vol. 19, 3-34, <www.jstor.org/stable/778652> (último acesso em 11/12/2020).

Lessa, Maria Silva Prado (2017), "Poema sobre palco. Cenas de Mário Cesariny”, Revista do CESP, vol. 37, $\mathrm{n}^{\circ}$ 58, 11-22, <http://www.periodicos.letras.ufmg.br/index.php/ cesp/article/view/12656/10954> (último acesso em 30/05/2021).

Lisboa, António Maria (2008), Poesia, organização e apresentação de Mário Cesariny, Lisboa, Assírio \& Alvim / Biblioteca de Editores Independentes.

Martelo, Rosa Maria (2012), "De imagem em imagem”, Abril - Revista do Núcleo de Estudos de Literatura Portuguesa e Africana da UFF, vol. 5, $\mathrm{n}^{\circ}$ 9, 15-26.

Paz, Octavio (1980), La búsqueda del comienzo (escritos sobre el surrealismo), $2^{\text {a }}$ edición, Madrid, Editorial Fundamentos.

Rajewsky, Irina (2018), "Percorsi transmediali. Appunti sul potenziale euristico della transmedialità nel campo delle letterature comparate”, Between, vol. 8, $n^{\circ} 16,1-30$, $<$ https://ojs.unica.it/index.php/between/article/view/3526/3140> (último acesso em 20/01/2021).

Rocha, Michele Coutinho (2017), “'Dizer no todo'. Palavra e imagem na obra de Mário Cesariny”, Visualidades, vol. 15, n² 2, 39-68, <https://www.revistas.ufg.br/VISUAL/ article/view/46479/24775> (último acesso em 20/01/2021).

-- (2018), Mário Cesariny e Joan Brossa. Para a transformação poética do homem, Centro Português do Surrealismo, Cadernos n. 17.

Rubin, William (1966), "Notes on Surrealism and Fantasy Art", Artforum, Special Issue, vol. 5, $\mathrm{n}^{\circ}$ 1, <https://www.artforum.com/print/196607/1-notes-on-surrealism-andfantasy-art-38888> (último acesso em 20/12/2020).

Taylor, Diana (2003), The Archive and The Repertoire. Cultural memory and performance in the Americas, Durham, Durham University Press.

Vasconcelos, Diana (2009), O Poeta-Mago. Presenças da Magia na Obra Poética de Mário Cesariny de Vasconcelos, dissertação de Mestrado em Estudos Literários, Culturais e Interartes (Literatura Portuguesa), Faculdade de Letras da Universidade do Porto. 